\title{
The grass is not always greener: a multi-institutional pilot study of marijuana use and acute pain management following traumatic injury
}

Kristin Salottolo ${ }^{1,2,3,4}$, Laura Peck ${ }^{5}$, Allen Tanner $\|^{6}$, Matthew M. Carrick ${ }^{7}$ Robert Madayag ${ }^{8}$, Emmett McGuire ${ }^{5}$ and David Bar-Or ${ }^{1,2,3,4^{*}}$

\begin{abstract}
Background: Widespread legislative efforts to legalize marijuana have increased the prevalence of marijuana use and abuse. The effects of marijuana on pain tolerance and analgesic pain management in the acute pain setting have not been reported. Although marijuana has been shown to have antinociceptive effects and is approved for medical use to treat chronic pain, anecdotal evidence suggests marijuana users admitted with traumatic injuries experience poorer pain control than patients who do not use marijuana. We hypothesized that marijuana users would report higher pain scores and require more opioid analgesia following traumatic injury.
\end{abstract}

Methods: This retrospective pilot study included all patients involved in motor vehicle crashes, consecutively admitted to four trauma centers from 1/1/2016-4/30/2016. Marijuana status was examined as non-use and use, and was further categorized as chronic and episodic use. We performed a repeated measures mixed model to examine the association between marijuana use and a) average daily opioid consumption and b) average daily pain scores (scale 0-10). Opioid analgesics were converted to be equianalgesic to $1 \mathrm{mg}$ IV hydromorphone.

Results: Marijuana use was reported in 21\% (54/261), of which 30\% reported chronic use (16/54). Marijuana use was reported more frequently in Colorado hospitals (23-29\%) compared to the hospital in Texas (6\%). Drug use with other prescription/street drugs was reported in $9 \%$ of patients. Other drug use was a significant effect modifier and results were presented after stratification by drug use. After adjustment, marijuana users who did not use other drugs consumed significantly more opioids ( $7.6 \mathrm{mg}$ vs. $5.6 \mathrm{mg}, p<0.001$ ) and reported higher pain scores (4.9 vs. 4.2 , $p<0.001)$ than non-marijuana users. Conversely, in patients who used other drugs, there were no differences in opioid consumption (5.6 mg vs. $6.1 \mathrm{mg}, p=0.70$ ) or pain scores (5.3 vs. 6.0, $p=0.07$ ) with marijuana use compared to non-use, after adjustment. Chronic marijuana use was associated with significantly higher opioid consumption compared to episodic marijuana use in concomitant drug users (11.3 mg vs. $4.4 \mathrm{mg}, p=0.008$ ) but was similar in non-drug users $(p=0.41)$.

Conclusion: These preliminary data suggest that marijuana use, especially chronic use, may affect pain response to injury by requiring greater use of opioid analgesia. These results were less pronounced in patients who used other drugs.

Keywords: Marijuana, Acute pain management, Vehicular trauma, Substance abuse

\footnotetext{
* Correspondence: dbaror@ampiopharma.com

${ }^{1}$ Trauma Research Department, Swedish Medical Center, 501 E. Hampden

Ave, Englewood, CO 80113, USA

${ }^{2}$ Trauma Research Department, St. Anthony Hospital, 11600 W. 2nd Place,

Lakewood, CO 80228, USA

Full list of author information is available at the end of the article
}

(c) The Author(s). 2018 Open Access This article is distributed under the terms of the Creative Commons Attribution 4.0 International License (http://creativecommons.org/licenses/by/4.0/), which permits unrestricted use, distribution, and reproduction in any medium, provided you give appropriate credit to the original author(s) and the source, provide a link to the Creative Commons license, and indicate if changes were made. The Creative Commons Public Domain Dedication waiver (http://creativecommons.org/publicdomain/zero/1.0/) applies to the data made available in this article, unless otherwise stated. 


\section{Background}

Substance abuse in the United States is on the rise, especially marijuana, ranking first in prevalence after alcohol [1]. Acute pain management among patients with substance abuse problems is challenging for numerous reasons, including drug cross-tolerance effects [2-4] and opioid-induced hyperalgesia and withdrawal $[5,6]$. The effects of marijuana use and abuse on acute pain management have not been addressed in prior studies and are poorly understood.

Marijuana was first used in the United States for alleviation of pain and spasticity [7]. Marijuana has recently been legalized in 29 states and the District of Columbia for medical and recreational use, due to the asserted medicinal effects and the perception of being a safe illicit substance. Marijuana's medicinal effects are largely antinociceptive, suggesting a role in treating chronic pain [8-11] and neuropathic pain [12, 13]. Other purported benefits include treatment of the signs and symptoms of multiple sclerosis, rheumatoid arthritis, glaucoma, epilepsy, inflammatory bowel disease, and emesis in HIV and cancer patients [14, 15]. However, there is only limited evidence from randomized controlled trials that marijuana and cannabinoids are effective for these latter proposed benefits [16].

It is necessary to understand how marijuana use affects pain management following traumatic injury for two reasons: first, the rapid proliferation of States legalizing marijuana for both medical and recreational use has increased its availability and use [17, 18]. Over 22 million people report using marijuana within the past month [1], of which $40.3 \%$ use it regularly (on 20 or more days). Second, patients with traumatic injuries have a higher prevalence of drug use than the general population, reported in $40-50 \%$ of trauma patients $[19,20]$, and the likelihood of a positive drug toxicology screen following trauma has increased over time [21]. Moreover, the risk of traffic accidents is increased more than two-fold in patients testing positive for marijuana [22], with an increase in fatal motor vehicle crashes (MVCs) since the legalization of medical marijuana in Colorado [23].

Although marijuana has been shown to have antinociceptive effects, anecdotal evidence at two of the included institutions suggests poorer pain control in marijuana users admitted with traumatic injuries. The objective of this study was to determine if there is an association between pre-injury marijuana use and pain response following traumatic injury.

\section{Methods}

The aims of the multi-institutional pilot study were to determine if there were differences, by marijuana use, in total daily opioid analgesics consumed and average daily pain scores.

The study population was identified from the Trauma Registry (TraumaBase; CDM, Evergreen, CO). Study inclusion criteria consisted of adults (Age $\geq 18$ ) admitted with a MVC (motor vehicle passenger/driver, motorcycle, auto-pedestrian) between January 1, 2016 - April 30, 2016 to four trauma centers: three level I centers (two centers in the Denver, $\mathrm{CO}$ metropolitan area and one in Plano, TX), and one level II trauma center located in Colorado Springs, CO. Patients with a hospital length of stay $(\mathrm{LOS})>14$ days were excluded. The study was approved from the Institutional Review Boards at each hospital.

The following were abstracted from the trauma registry in real time by dedicated trauma registrars for all trauma patients: demographics (age, gender), arrival blood alcohol concentration (BAC, $\geq 80 \mathrm{mg} / \mathrm{dl}$ was defined as intoxication), urine drug screen (UDS) performed (yes/no) as well as positive results on the standard multi-drug UDS panel (positive for any of the following: amphetamines, barbiturates, benzodiazepines, cocaine, methamphetamine, opiates, and marijuana (tetrahydrocannabinol [THC]), injury severity score (ISS), injury mechanism (motor vehicle, motorcycle, auto-pedestrian), admission Glasgow coma scale (GCS) score, and clinical outcomes (mortality, hospital LOS, intensive care unit (ICU) LOS).

The following substance use information was abstracted from the electronic medial record: current substance use obtained from patient history and drug and alcohol screening with the screening, brief intervention, and referral to treatment (SBIRT) screen, CAGE questionnaire, or Alcohol, Smoking and Substance Involvement Screening Test (ASSIST); frequency of marijuana use, usually recorded as times used per day / week / month; amount of marijuana used, recorded as amount of "joints", vapor hits, "edibles", etc.

Additional information abstracted from the electronic medical record included: pain scores using standardized pain numeric rating scale (NRS, 0-10 scale), recorded as date and time and score; analgesic medication use, including date and time, dose, and route of administration; analgesics received at discharge, including dose and route of administration. Pain medication orders are similar in the ICU and on the medical floor. Standard practice is for patients to rate their pain every time an analgesic is administered and when analgesic orders are adjusted.

\section{Analysis}

All analyses were performed using SAS version 9.3 (Cary, NC). Marijuana use was defined as self-reported current use of marijuana or as a positive UDS result for marijuana (THC). Chronic marijuana use was defined as 
self-reported daily or almost daily use or more than one ounce of marijuana over the past month. All other marijuana users were considered episodic users. Drug use, other than marijuana, was defined as self-reported current use/abuse of street or prescription drugs or a positive UDS result for amphetamines, barbiturates, benzodiazepines, cocaine, methamphetamines, opiates, or PCP.

Opioids are the mainstay analgesics for managing pain in the traumatic and critical care setting due to their proven efficacy in treating moderate to severe acute pain $[24,25]$. Analgesics were classified as opioids and non-opioids, and all opioids were converted to be equianalgesic to $1 \mathrm{mg}$ hydromorphone using an equianalgesic conversion chart. The amount of opioids consumed was summed for each 24-h period from admission through discharge; this total daily opioid count takes into account dose and frequency (Fig. 1). A square root transformation was used for opioid consumption to ensure a normal distribution in the final models; results are presented using back-transformed data. Pain scores were normally distributed; average daily pain NRS scores were calculated for each 24-h period from admission through discharge (Fig. 2).

Differences, by marijuana status, in total daily opioid analgesics consumed and average daily pain scores were examined with repeated measures mixed models. We tested for possible interactions for study covariates; drug use was a significant effect modifier, and all final models were seperately examined and reported for drug users (i.e. amphetamines, barbiturates, benzodiazepines, cocaine, methamphetamines, opiates, or PCP) and non-drug users. Final models are presented before adjustment and after adjustment for ISS, age, and specific cause of injury. All models were performed in marijuana users vs. non-using patients, and then chronic marijuana use vs. episodic use vs. non-users. Statistical significance was set at $p<0.05$.

\section{Results}

Marijuana use was reported in 21\% (54/261) of patients, of which $30 \%$ reported chronic use (16/54). Marijuana
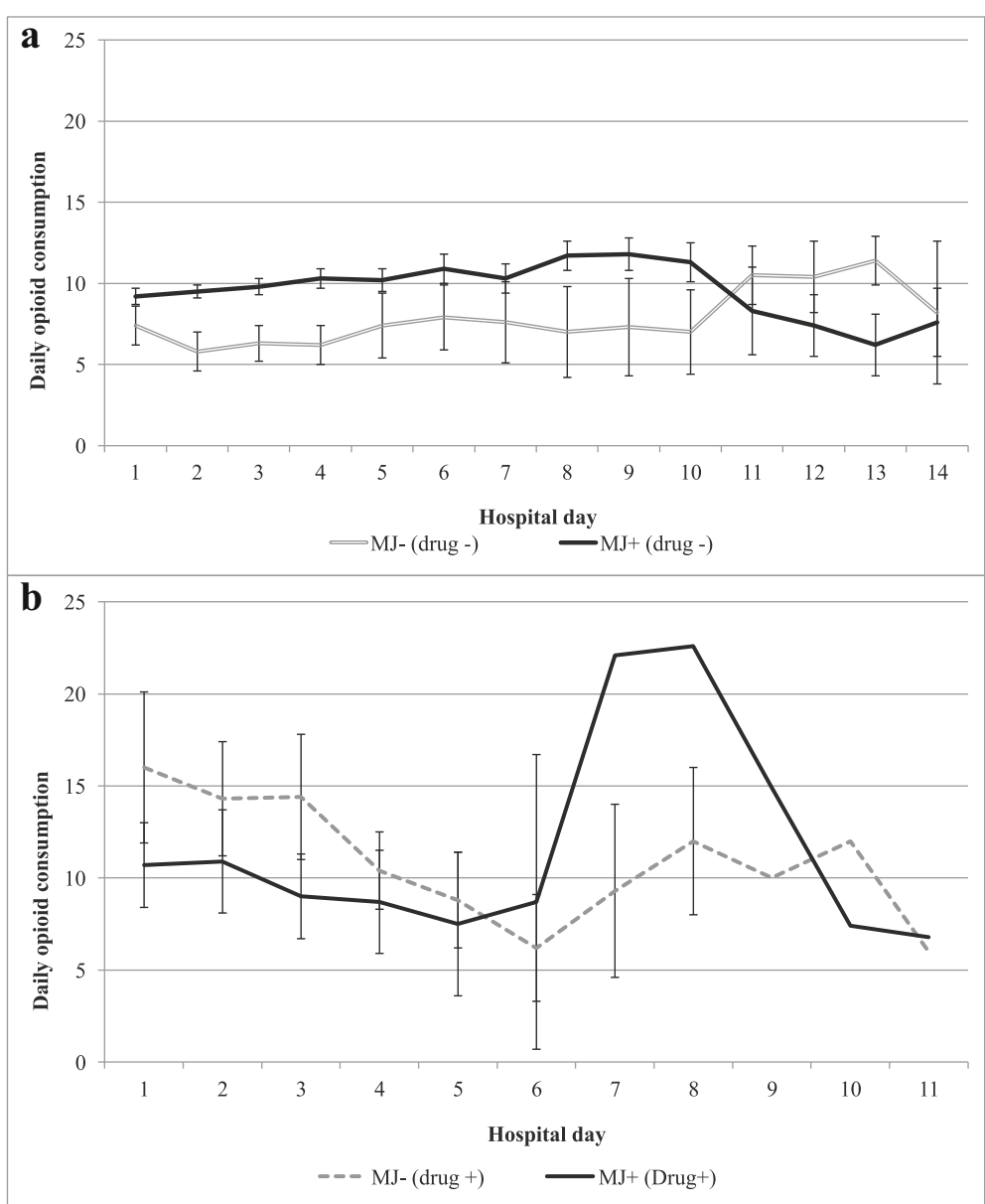

Fig. 1 Average total daily opioid analgesics consumed, by marijuana (MJ) use in a non-drug users and $\mathbf{b}$ drug users (amphetamines, barbiturates, benzodiazepines, cocaine, opiates, PCP, or methamphetamine). Opioids were converted to be equianalgesic to 1 mg hydromorphone 


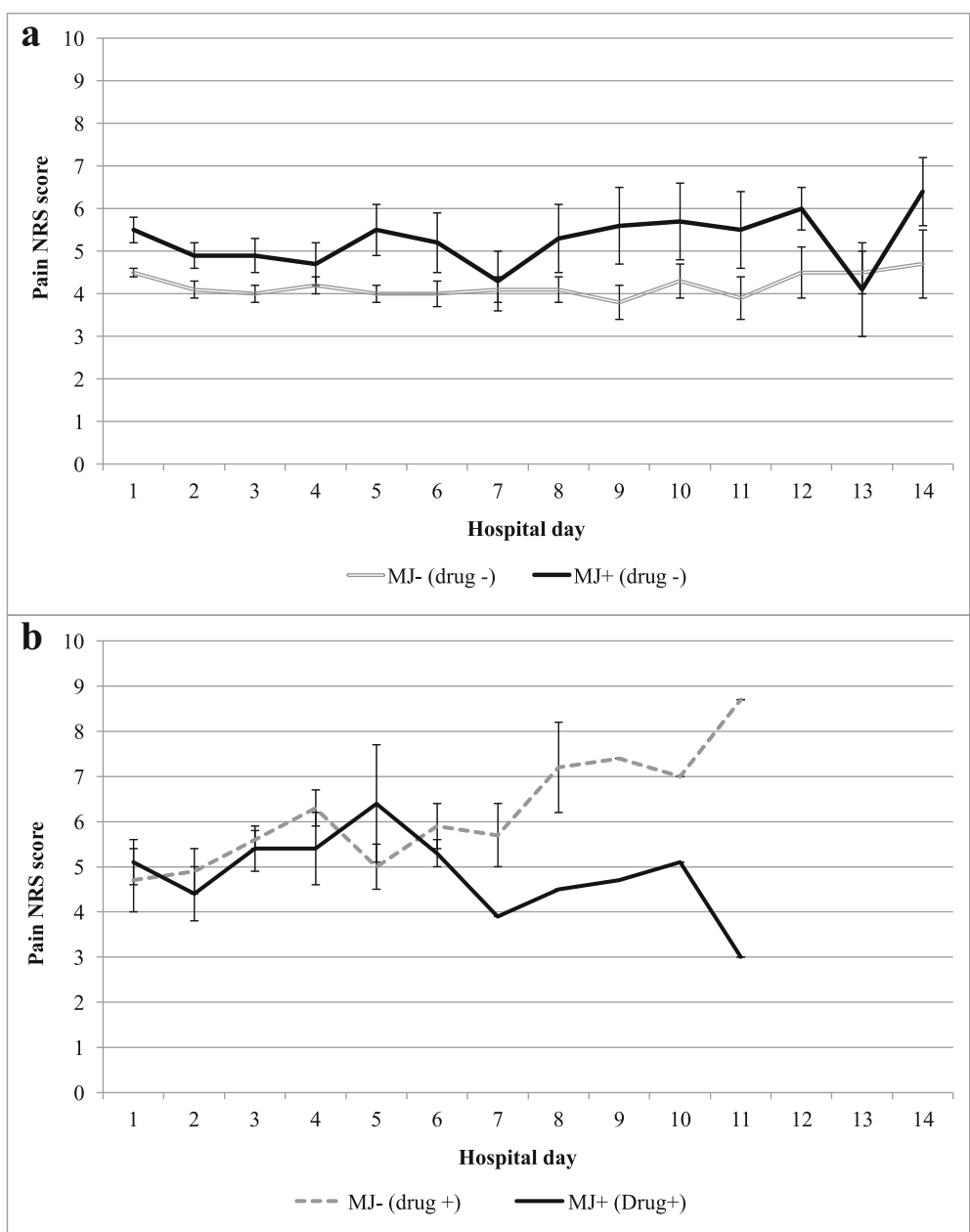

Fig. 2 Average daily pain numeric rating scale (NRS) scores by marijuana (MJ) use in a non-drug users and $\mathbf{b}$ drug users (amphetamines, barbiturates, benzodiazepines, cocaine, methamphetamine, opiates). Patients are instructed that pain scores should be four or less, where scores of zero are not expected

use was reported more frequently in Colorado hospitals (23-29\%) compared to the hospital in Texas (6\%). The majority of patients did not specify the indication for use (51\%); in those who did, $78 \%$ reported recreational use and $22 \%$ reported medical use. Compared to compared to non-users, marijuana userswere more likely to be younger ( 28 years vs. 46 years), and use drugs besides marijuana ( $26 \%$ vs. $4 \%$ ), Table 1 . There were no differences by marijuana status in gender, cause of vehicular trauma, GCS, ISS, alcohol intoxication, and no differences in any of the clinical outcomes (Table 1). There were also no differences in demographics, injury characteristics, and clinical outcomes between chronic and episodic marijuana users (Table 1).

In total 5863 analgesic doses were consumed over the hospitalization; the majority (86\%) of the analgesics were opioids. The most commonly administered opioids were hydromorphone (dilaudid), accounting for $27 \%$ of all opioids consumed, oxycodone (26\%), hydrocodone (11\%) fentanyl (10\%), morphine (10\%), and tramadol (2\%); codeine, methadone, meperedine, and nalbuphine were prescribed $<1 \%$ of the time. Throughout the hospitalization there were 7345 pain scores recorded, or an average of 7.7 pain assessments/patient/day.

\section{Results, non-drug users}

Overall, 91\% of patients did not test positive for drugs (i.e. amphetamines, barbiturates, benzodiazepines, cocaine, methamphetamine, or opiates). In this majority, marijuana users received significantly more opioid analgesics than non-marijuana users, both before (Fig. 1a) and after adjustment (Table 2). Compared to non-marijuana users, opioid use was greater in chronic marijuana users (7.1 vs. $5.7 \mathrm{mg}, p=0.049)$ and episodic users $(7.8 \mathrm{mg}$ vs. $5.7 \mathrm{mg}, p<0.001)$. Chronic marijuana users reported similar opioid analgesic consumption compared to episodic marijuana users $(p=0.41)$. 
Table 1 Characteristics and outcomes, by marijuana status

\begin{tabular}{|c|c|c|c|c|c|c|}
\hline Characteristic $(\%, n)$ & $\begin{array}{l}\text { Marijuana user } \\
n=54\end{array}$ & $\begin{array}{l}\text { Non-user } \\
n=207\end{array}$ & $p$ value & $\begin{array}{l}\text { Chronic marijuana user } \\
n=15\end{array}$ & $\begin{array}{l}\text { Episodic marijuana use } \\
n=38\end{array}$ & $p$ value \\
\hline Male sex & $61 \%(33)$ & $61 \%(126)$ & 0.97 & $63 \%(10)$ & $61 \%(23)$ & 0.89 \\
\hline Age, years ${ }^{a}$ & $28(23-39)$ & $46(26-65)$ & $<0.001$ & $23(22-43)$ & $29(23-38)$ & 0.37 \\
\hline Cause of injury & & & 0.08 & & & 0.43 \\
\hline Motor vehicle & $80 \%(43)$ & $80 \%(166)$ & & $69 \%(11)$ & $84 \%(32)$ & \\
\hline Motorcycle & $4 \%(2)$ & $11 \%(23)$ & & $6 \%(1)$ & $3 \%(1)$ & \\
\hline Pedestrian & $17 \%(9)$ & $9 \%(18)$ & & $25 \%(4)$ & $13 \%(5)$ & \\
\hline Normal Glasgow coma score 15 & $83 \%(45)$ & $81 \%(168)$ & 0.71 & $75 \%(12)$ & $87 \%(33)$ & 0.42 \\
\hline Injury severity score ISS & $9.5(4-17)$ & $9(5-14)$ & 0.74 & $7(3.5-15.5)$ & $10(4-17)$ & 0.37 \\
\hline Intoxicated (BAC $\geq 80$ mg/dL) & $26 \%(11)$ & $25 \%(35)$ & 0.98 & $31 \%(4)$ & $23 \%(7)$ & 0.71 \\
\hline Urine drug screen (UDS) performed & $77 \%(41)$ & $68 \%(135)$ & 0.17 & $81 \%(13)$ & $76 \%(28)$ & 0.74 \\
\hline Positive UDS for drugs ${ }^{b}$ & $22 \%(12)$ & $2 \%(5)$ & $<0.001$ & $13 \%(2)$ & $26 \%(10)$ & 0.47 \\
\hline Drugs user (UDS/self-report) ${ }^{b}$ & $26 \%(14)$ & $4 \%(9)$ & $<0.001$ & $13 \%(2)$ & $32 \%(12)$ & 0.19 \\
\hline \multicolumn{7}{|l|}{ Clinical outcome } \\
\hline Mortality & $0 \%(0)$ & $2 \%(5)$ & 0.59 & $0 \%(0)$ & $0 \%(0)$ & - \\
\hline LOS, days $^{a}$ & $2(1-5)$ & $3(1-6)$ & 0.57 & $3(2-6)$ & $2(1-4)$ & 0.35 \\
\hline ICU LOS, days ${ }^{\mathrm{a}}$ & $1.5(0-4)$ & $2(0-5)$ & 0.81 & $1.5(0-3)$ & $1.5(0-4.5)$ & 0.89 \\
\hline
\end{tabular}

MJ marijuana, ICU intensive care unit, LOS length of stay

${ }^{\mathrm{a}}$ Data presented as median (IQR)

bDrugs: amphetamines, barbiturates, benzodiazepines, cocaine, methamphetamine, opiates

$P<0.05$ in italic is clinically significant

Pain scores were significantly greater over the hospitalization for marijuana users compared to non-users, both before (Fig. 2a) and after adjustment (Table 2). When the frequency of marijuana use was examined, episodic marijuana users reported higher pain scores than chronic marijuana users (5.3 vs. 4.2, $\mathrm{p}$ $<0.001$ ) as well as non-users (5.3 vs. $4.2, p<0.001)$.

\section{Results, drug users}

Nine percent of patients tested positive for drugs (i.e. amphetamines, barbiturates, benzodiazepines, cocaine, methamphetamine, or opiates). Opioid consumption was not significantly different in drug users who also used marijuana compared to drug users who did not use marijuana, both before (Fig. 1b) and after adjustment

Table 2 Mean (standard error) daily opioid consumption and daily pain numeric rating scale (NRS) scores, by marijuana status and other drug use

\begin{tabular}{llll}
\hline Outcome, stratified & Marijuana user $(n=54)$ & No marijuana use $(n=207)$ & $p$ value \\
\hline No other drug use ${ }^{\text {a }}$ & $(n=40)$ & $(n=198)$ & $<0.001$ \\
Mean opioid consumption & $8.53(0.33)$ & $5.86(0.18)$ & $<0.001$ \\
LSM $^{b}$ opioid consumption & $7.57(0.36)$ & $5.65(0.18)$ & $<.17(0.07)$ \\
Mean pain NRS score & $5.17(0.15)$ & $4.19(0.11)$ & $<01$ \\
LSM $^{b}$ mean pain NRS score & $4.92(0.16)$ & $(n=9)$ & 0.001 \\
Other drug use & $(n=14)$ & $10.58(0.97)$ & 0.29 \\
Mean opioid consumption & $8.81(0.82)$ & $6.10(1.17)$ & 0.71 \\
LSM $^{b}$ opioid consumption & $5.59(0.81)$ & $5.54(0.25)$ & 0.15 \\
Mean pain NRS score & $5.02(0.24)$ & $6.00(0.48)$ & 0.07 \\
LSM $^{b}$ mean pain NRS score & $5.28(0.34)$ & & \\
\hline
\end{tabular}

Analyzed with a repeated measures linear mixed model

LSM least square mean

${ }^{a}$ Drug use: amphetamines, barbiturates, benzodiazepines, cocaine, methamphetamine, and opiates

${ }^{b}$ Adjusted for ISS, age, and cause of motor vehicle crash injury

$P<0.05$ in italic is clinically significant 
(Table 2). However, drug users who chronically used marijuana reported the highest opioid analgesic consumption relative to episodic marijuana use $(11.3 \mathrm{mg}$ vs. $4.4 \mathrm{mg}, p=0.01)$ and non-marijuana use (11.3 $\mathrm{mg}$ vs. $6.2 \mathrm{mg}, p=0.05$ ), after adjustment.

Pain scores were not significantly different in drug users who also used marijuana compared to those who did not use marijuana, both before (Fig. 2b) and after adjustment (Table 2). However, when further examined by frequency of marijuana use, drug users who did not use marijuana reported higher pain scores relative to drug users who used marijuana chronically (6.2 vs. 4.6, $\mathrm{p}=0.01)$ and episodically (6.2 vs. $5.7, p=0.06$ ).

\section{Discussion}

The primary findings from this pilot study suggest that marijuana use significantly affects acute pain management and results in increased consumption of opioid analgesics and greater self-reported pain following traumatic injury, especially in patients who did not report using other drugs. We also identified a low prevalence of other drug use but a relatively high prevalence of chronic marijuana use among trauma patients, especially in trauma centers in Colorado where marijuana has been legalized for both medical and recreational use.

To our knowledge, this is the first study to examine the effect of marijuana use and abuse on acute pain management following traumatic injury. We observed that marijuana's effect on pain was modified by concomitant drug use. In drug users the addition of marijuana did not appear to effect opioid consumption unless it was used chronically. In non-drug users (representing $91 \%$ of our population), opioid administration over the course of the hospital stay was greatest for trauma patients who had used marijuana, both for chronic and episodic use compared to non-marijuana users, even after adjustment for injury severity, age, and specific type of MVC. This translates to a $25-37 \%$ increase in opioid consumption for marijuana users than non-marijuana users. Additionally, pain scores were significantly higher in marijuana users compared to non-users, even after adjustment for relevant confounders. The difference in pain scores in marijauna users vs. non-users (5.3 vs. 4.2$)$ is striking when considering that pain scores $\leq 4$ on a $0-10$ scale are mild/ moderate and scores of $\geq 5$ are considered severe [26].

Prior studies report changes in acute pain management in opioid-tolerant patients, including an increase in opioid consumption [27-29]. Patanwala et al. were the first to prospectively compare the effect of opioid tolerance on the post-surgical analgesic response to opioids, demonstrating a significant increase in opioid consumption and greater pain NRS scores immediately after total knee arthroplasty in opioid tolerant patients relative to the naïve group [28]. Other studies examining opioid tolerance and post-operative pain management reported greater use of analgesics [29], and greater post-surgical requirement for epidural anesthesia [27] in patients who had prior opioid treatment. Neighbor and colleagues examined illegal substance abuse in the emergency department, which included cocaine, heroin, and amphetamine, reporting that substance abusers had significantly higher pain NRS scores compared to non-substance abusers at triage (8.96 vs. 7.81, $p=0.003$ ) [30]. We also identified an association between marijuana use and abuse with acute pain management, and much like the opioid tolerant populations, identified chronic use of marijuana resulted in the greatest need for increased analgesia following injury.

Trauma patients commonly have substance abuse issues or other positive toxicology findings. There was a low prevalence of other drug use but a relatively high prevalence of chronic marijuana use, especially in trauma centers in Colorado. In our study $25 \%$ were acutely intoxicated, $21 \%$ used marijuana, and $9 \%$ used other drugs. Marijuana use was reported approximately 4 times more frequently in Colorado hospitals compared to the hospital in Texas. While the study is not designed to point to any causality related to the permissive marijuana laws, we were impressed by the prevalence of marijuana usage amongst our trauma populations. There appears to be a profound increase in marijuana use amongst trauma patients in the states with permissive marijuana laws. It is possible that the increased marijuana use leads to more motor vehicle collisions, but it is not possible to draw this conclusion based upon our data. This study should serve as a call to action for more research into the topic of legalization of marijuana.

We believe the increasing prevalence of marijuana use and other substance abuse issues will have clinical implications for acute pain management. Specifically, these data suggest that patients with marijuana use and abuse issues merit special consideration during acute pain management. These data may help set reasonable expectations for patients regarding the severity and duration of pain they experience, and could help clinicians recognize patients that are more likely to experience suboptimal pain management.

Despite its generally illicit status globally and its schedule I status in the US, there is a growing body of research examining endogenous cannabinoids (endocannabinoids) and exogenous cannabinoids as a target of pharmacotherapy [15]. Several endocannabinoids function to suppress pain sensitivity through their binding to the G-coupled CB1 and CB2 receptors [31]. The activation of these cannabinoid receptors inhibits calcium channels, resulting in activation of potassium channels and decreases in neurotransmitter release from several tissues [32, 33], including inhibition of norepinephrine 
release from sympathetic nerve terminals and diminished sympathetically mediated pain [15]. This activation of the cannabinoid receptors may be a potential mechanism of action for the antinociceptive effects of cannabinoids [34]. However, the antinociceptive effects of cannabinoids may respond to inflammatory, neurogenic, and chronic pain better than acutely evoked pain [35]. Other studies have demonstrated that the binding of endocannabinioids to $\mathrm{CB} 1$ receptors unexpectedly resulted in pain sensitization in in-vivo experiments, and may increase the risk of turning acute pain into chronic pain [36]. Thus, it is plausible that cannabis may be beneficial in treating chronic pain but may be detrimental in the acute pain setting.

There are study limitations. Primarily, this is a pilot study. Some subgroup sizes are low and possibly too small to draw valid conclusions. However, this is a pilot trial and is used as hypothesis generating in order to plan future studies. In the planned prospective study, approximately 360 patients are needed to adequately power the study. Second, the study has many of the disadvantages of a retrospective chart review. For instance, there is the possibility of exposure misclassification: patients were considered non-users if they had no urine drug toxicology screen or a negative toxicology screen and did not self-report using marijuana. Also, marijuana users without details on frequency of use were considered episodic users. Third, our findings might not be generalizable because we excluded minors and we chose to focus on patients who sustained MVC injuries because this population was thought to contain a high concentration of marijuana users. Marijuana consumption also increases the risk of non-traffic injuries, in particular falls in older adults [37], which is a population of interest for future study. Fourth, we excluded patients with a LOS $>14$ days ( $10 \%$ of the population), because there is the possibility that the amount of opioids received for pain management over several weeks might lead to acute tolerance and increased opioid consumption unrelated to pre-injury drug and marijuana use [38]. Fifth, 14\% of analgesics were non-opioids; we did not report differences in non-opioid analgesics, in part because of there is no standard approach to converting to equianalgesic doses. However, multimodal analgesia can achieve opioid-sparing effects, thereby affecting the data reported for opioid consumption. Lastly, patients who are conscious but non-verbal use a picture face scale, which also utilizes a pain NRS but there are fewer categories: 0 (no pain), 2 (just a little bit) 4 (hurts a little more), 6 (hurts even more), 8 (hurts a whole lot), and 10 (hurts as much as you can imagine). Only the anchor points of 0 and 10 are directly comparable to the pain NRS (0-10). Pain scores may be less accurate in patients with more severe injuries. This limitation should not bias our findings because there were no differences in injury severity (ISS or GCS) between marijuana users and non-users.

\section{Conclusions}

These preliminary data suggest that marijuana use, especially chronic use, may affect pain response to injury by requiring greater frequency and dosing of opioid analgesia. These results were less pronounced in patients who used other drugs. With the increasing prevalence of marijuana use and abuse, and the frequency in which patients with traumatic injury also report substance abuse, our findings have important and potentially well reaching clinical implications. We are planning a larger prospective study to further investigate the relationship between substance use, opioid analgesics, and acute pain management in traumatic injury.

\section{Abbreviations \\ ASSIST: Alcohol Smoking and Substance Involvement Screening Test: BAC: Blood alcohol concentration; GCS: Glasgow coma scale (GCS); ICU: Intensive care unit; ISS: Injury severity score; LOS: Length of stay; MVC: Motor vehicle crash; NRS: Numeric rating score; SBIRT: Screening, brief intervention, and referral to treatment; THC: Tetrahydrocannabinol; UDS: Urine drug screen}

\section{Acknowledgements \\ We would like to acknowledge the hard work of the trauma research assistants and study coordinators who performed the detailed chart review, without which this research would not have been possible: Barbara Shaffer, Gina Mallory, Ingrid Ingham, Diane Redmond, Jennifer Pekarek, and Kimberly Aumann.}

\section{Funding}

The study was investigator initiated. Internal funding was provided by Swedish Medical Center, St. Anthony Hospital, Penrose Hospital, and Medical City Plano.

\section{Availability of data and materials \\ The datasets used and/or analysed during the current study are available from the corresponding author on reasonable request.}

\section{Authors' contributions}

Ms. Salottolo is responsible for literature search, design, data acquisition, data analysis, interpretation of data, and drafting the manuscript. Drs. McGuire and Peck are responsible for study conception, literature search, interpretation of the data, and critical revisions. Drs. Mains, Madayag and Tanner are responsible for interpretation of the data and critical revisions. Dr. Bar-Or is responsible for interpretation of the data and drafting the manuscript. All authors provided final approval of the submitted manuscript.

\section{Ethics approval and consent to participate}

The study was approved from the Institutional Review Boards at each respective facility; informed consent was waived. Reference numbers: Swedish Medical Center: 987891; St. Anthony Hospital: 973145; Penrose Hospital: 975740; Medical City Plano: 103099.

\section{Competing interests}

The authors declare that they have no competing interests.

\section{Publisher's Note}

Springer Nature remains neutral with regard to jurisdictional claims in published maps and institutional affiliations. 


\section{Author details}

${ }^{1}$ Trauma Research Department, Swedish Medical Center, 501 E. Hampden Ave, Englewood, CO 80113, USA. ${ }^{2}$ Trauma Research Department, St. Anthony Hospital, 11600 W. 2nd Place, Lakewood, CO 80228, USA. ${ }^{3}$ Trauma Research Department, Medical City Plano, 3901 West 15th Street, Plano, TX 75075, USA. ${ }^{4}$ Trauma Research Department, Penrose Hospital, 2222 N Nevada Drive, Colorado Springs, CO 80907, USA. ${ }^{5}$ Trauma Services Department, Swedish Medical Center, 499 E. Hampden Ave, Englewood, CO 80113, USA. ${ }^{6}$ Trauma Services Department, Penrose Hospital, 2222 N Nevada Drive, Colorado Springs, CO 80907, USA. ${ }^{7}$ Trauma Services Department, Medical City Plano, 3901 W 15th St, Plano, TX 75075, USA. ${ }^{8}$ Trauma Services Department, St. Anthony Hospital, 11600 West 2nd Place, Lakewood, CO 80228, USA.

Received: 8 March 2018 Accepted: 24 May 2018

Published online: 19 June 2018

\section{References}

1. Center for Behavioral Health Statistics and Quality. Behavioral health trends in the United States: Results from the 2014 National Survey on Drug Use and Health (HHS Publication No. SMA 15-4927 NSDUH Series H-50). 2015. Retrieved from http://www.samhsa.gov/data/.

2. Askay SW, Bombardier CH, Patterson DR. Effect of acute and chronic alcohol abuse on pain management in a trauma center. Expert Rev Neurother. 2009:9:271-7.

3. Cohen SP, Christo PJ, Moroz L. Pain management in trauma patients. Am J Phys Med Rehabil. 2004:83:142-61.

4. Heiskanen T, Kalso E. Non-analgesic effects of opioids: interactions between opioids and other drugs. Curr Pharm Des. 2012;18:6079-89.

5. Huxtable CA, Roberts $\amalg$, Somogyi AA, Maclntyre PE. Acute pain management in opioid-tolerant patients: a growing challenge. Anaesth Intensive Care. 2011;39:804-23.

6. Silverman SM. Opioid induced hyperalgesia: clinical implications for the pain practitioner. Pain Physician. 2009;12:679-84.

7. Wood G. The dispensary of the United States of America. Philadelphia: Lippincott and Grambo; 1854.

8. Fine PG, Rosenfeld MJ. The endocannabinoid system, cannabinoids, and pain. Rambam Maimonides Med J. 2013:4:e0022.

9. Martin-Sanchez E, Furukawa TA, Taylor J, Martin JL. Systematic review and meta-analysis of cannabis treatment for chronic pain. Pain medicine (MaldenMass). 2009;10:1353-68.

10. Rog DJ, Nurmikko TJ, Friede T, Young CA. Randomized, controlled trial of cannabis-based medicine in central pain in multiple sclerosis. Neurology. 2005;65:812-9

11. Ware MA, Wang T, Shapiro S, Robinson A, Ducruet T, Huynh T, et al. Smoked cannabis for chronic neuropathic pain: a randomized controlled trial. CMAJ. 2010;182:E694-701.

12. Wilsey B, Marcotte T, Deutsch R, Gouaux B, Sakai S, Donaghe H. Low-dose vaporized cannabis significantly improves neuropathic pain. J Pain. 2013;14:136-48

13. Wilsey B, Marcotte T, Tsodikov A, Millman J, Bentley H, Gouaux B, et al. A randomized, placebo-controlled, crossover trial of cannabis cigarettes in neuropathic pain. J Pain. 2008;9:506-21.

14. Greydanus DE, Hawver EK, Greydanus MM, Merrick J. Marijuana: current concepts(dagger). Front Public Health. 2013;1:42.

15. Pacher $P$, Batkai $S$, Kunos $G$. The endocannabinoid system as an emerging target of pharmacotherapy. Pharmacol Rev. 2006;58:389-462.

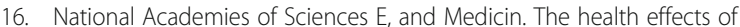
cannabis and cannabinoids: The current state of evidence and recommendations for research. Washington, DC: The National Academies Press; 2017

17. Ghosh TS, Van Dyke M, Maffey A, Whitley E, Erpelding D, Wolk L. Medical marijuana's public health lessons-implications for retail marijuana in Colorado. N Engl J Med. 2015;372:991-3.

18. Monte $\mathrm{AA}$, Zane RD, Heard $\mathrm{K}$. The implications of marijuana legalization in Colorado. JAMA. 2015;313:241-2.

19. Cowperthwaite MC, Burnett MG. Treatment course and outcomes following drug and alcohol-related traumatic injuries. J Trauma Manag Outcomes. 2011;5:3.

20. Rivara FP, Jurkovich GJ, Gurney JG, Seguin D, Fligner $C L$, Ries $R$, et al. The magnitude of acute and chronic alcohol abuse in trauma patients. Arch Surg (Chicago, III : 1960). 1993;128:907-12. discussion 12-3
21. London JA, Battistella FD. Testing for substance use in trauma patients: are we doing enough? Arch Surg (Chicago, III : 1960). 2007;142:633-8.

22. Li MC, Brady JE, DiMaggio CJ, Lusardi AR, Tzong KY, Li G. Marijuana use and motor vehicle crashes. Epidemiol Rev. 2012:34:65-72.

23. Salomonsen-Sautel S, Min SJ, Sakai JT, Thurstone C, Hopfer C. Trends in fatal motor vehicle crashes before and after marijuana commercialization in Colorado. Drug Alcohol Depend. 2014;140:137-44.

24. Gaskell H, Derry S, Moore RA, McQuay HJ. Single dose oral oxycodone and oxycodone plus paracetamol (acetaminophen) for acute postoperative pain in adults. Cochrane Database Syst Rev. 2009;3:Cd002763.

25. Minkowitz HS, Rathmell JP, Vallow S, Gargiulo K, Damaraju CV, Hewitt DJ. Efficacy and safety of the fentanyl iontophoretic transdermal system (ITS) and intravenous patient-controlled analgesia (IV PCA) with morphine for pain management following abdominal or pelvic surgery. Pain Med (Malden, Mass). 2007:8:657-68.

26. Gerbershagen HJ, Rothaug J, Kalkman CJ, Meissner W. Determination of moderate-to-severe postoperative pain on the numeric rating scale: a cut-off point analysis applying four different methods. $\mathrm{Br} J$ Anaesth. 2011;107:619-26.

27. de Leon-Casasola OA, Myers DP, Donaparthi S, Bacon DR, Peppriell J, Rempel J, et al. A comparison of postoperative epidural analgesia between patients with chronic cancer taking high doses of oral opioids versus opioid-naive patients. Anesth Analg. 1993;76:302-7.

28. Patanwala AE, Jarzyna DL, Miller MD, Erstad BL. Comparison of opioid requirements and analgesic response in opioid-tolerant versus opioid-naive patients after total knee arthroplasty. Pharmacotherapy. 2008:28:1453-60.

29. Rapp SE, Ready LB, Nessly ML. Acute pain management in patients with prior opioid consumption: a case-controlled retrospective review. Pain. 1995;61:195-201.

30. Neighbor ML, Dance TR, Hawk M, Kohn MA. Heightened pain perception in illicit substance-using patients in the ED: implications for management. Am J Emerg Med. 2011;29:50-6.

31. Walker JM, Krey JF, Chu CJ, Huang SM. Endocannabinoids and related fatty acid derivatives in pain modulation. Chem Phys Lipids. 2002;121:159-72.

32. Mackie K, Lai Y, Westenbroek R, Mitchell R. Cannabinoids activate an inwardly rectifying potassium conductance and inhibit Q-type calcium currents in AtT20 cells transfected with rat brain cannabinoid receptor. J Neurosci. 1995;15:6552-61.

33. Twitchell W, Brown S, Mackie K. Cannabinoids inhibit N- and P/Q-type calcium channels in cultured rat hippocampal neurons. J Neurophysiol. 1997;78:43-50

34. Ameri A. The effects of cannabinoids on the brain. Prog Neurobiol. 1999;58:315-48

35. McPartland JM. The endocannabinoid system: an osteopathic perspective. J Am Osteopath Assoc. 2008;108:586-600.

36. Pernia-Andrade AJ, Kato A, Witschi R, Nyilas R, Katona I, Freund TF, et al. Spinal endocannabinoids and CB1 receptors mediate C-fiber-induced heterosynaptic pain sensitization. Science. 2009;325:760-4.

37. Barrio G, Jimenez-Mejias E, Pulido J, Lardelli-Claret P, Bravo MJ, de la Fuente L. Association between cannabis use and non-traffic injuries. Accid Anal Prev. 2012;47:172-6.

38. Dumas EO, Pollack GM. Opioid tolerance development: a pharmacokinetic/ pharmacodynamic perspective. AAPS J. 2008;10:537-51.

Ready to submit your research? Choose BMC and benefit from:

- fast, convenient online submission

- thorough peer review by experienced researchers in your field

- rapid publication on acceptance

- support for research data, including large and complex data types

- gold Open Access which fosters wider collaboration and increased citations

- maximum visibility for your research: over $100 \mathrm{M}$ website views per year

At BMC, research is always in progress.

Learn more biomedcentral.com/submissions 